\title{
LA PARACENTESIS Y EL MASAJE OCULAR COMO TRATAMIENTO DE LA OCLUSIÓN DE LA ARTERIA CENTRAL DE LA RETINA
}

\author{
BARBÓN-GARCÍA JJ ${ }^{1}$, ÁLVAREZ-SUÁREZ ML ${ }^{2}$
}

La oftalmología se desarrolló fundamentalmente como especialidad a lo largo del s. XIX con importantes aportaciones en los estudios médicos del ojo, el nacimiento de revistas especializadas y también con la fundación de las primeras sociedades oftalmológicas. En el s. XX se impuso la tecnología aplicada a la oftalmología con una innovación continua, por lo que resulta sorprendente encontrarnos con patologías que apenas han sufrido variaciones en su tratamiento desde el s. XIX, como sucede con la obstrucción de la arteria central de la retina.

En el Tratado de enfermedades de los ojos de Ernst Fuchs (Viena 1851-1930), un clásico en su tiempo que se mantuvo 50 años vigente en sucesivas reediciones, aparece esta brillante y sucinta descripción sobre la oclusión de la arteria central de la retina y su tratamiento, mediante masaje y paracentesis, que aún hoy puede suscribirse. El libro de Fuchs, cuya 1. a edición en alemán se había publicado en 1889, se editó en castellano en el año 1893, en dos pequeños tomos y dentro de la Biblioteca Escogida de El siglo Médico traducido por el Dr. Víctor Cebrián, médico del Hospital Provincial de Madrid.

Escribe Fuchs en el capítulo 3 del 2. ${ }^{\circ}$ tomo, titulado Enfermedades de la retina: «Llama la atención del enfermo sobre su enfermedad la ceguera súbita y completa de que se siente atacado en el momento en que se oblitera la arteria. Cuando inmediatamente después del accidente, se examina el ojo al oftalmoscopio, se encuentran los signos de una anemia arterial profunda de la retina. Las grandes arterias están reducidas a filamentos delgados, y las pequeñas se han hecho invisibles ... En poco tiempo, con frecuencia en algunas horas, la retina muere y pierde su transparencia, se torna de un blanco lechoso, sobre todo en el contorno de la papila y en la región de la mácula. Al nivel de la mancha amarilla, sobre el fondo blanco y opaco, se dibuja una de un color rojo vivo... Después, la opacidad retiniana desaparece, y la retina adquiere de nuevo su transparencia, pero se atrofia por completo. La papila del nervio óptico es más blanca, los vasos son escasos, delgados como hilos, tanto en la

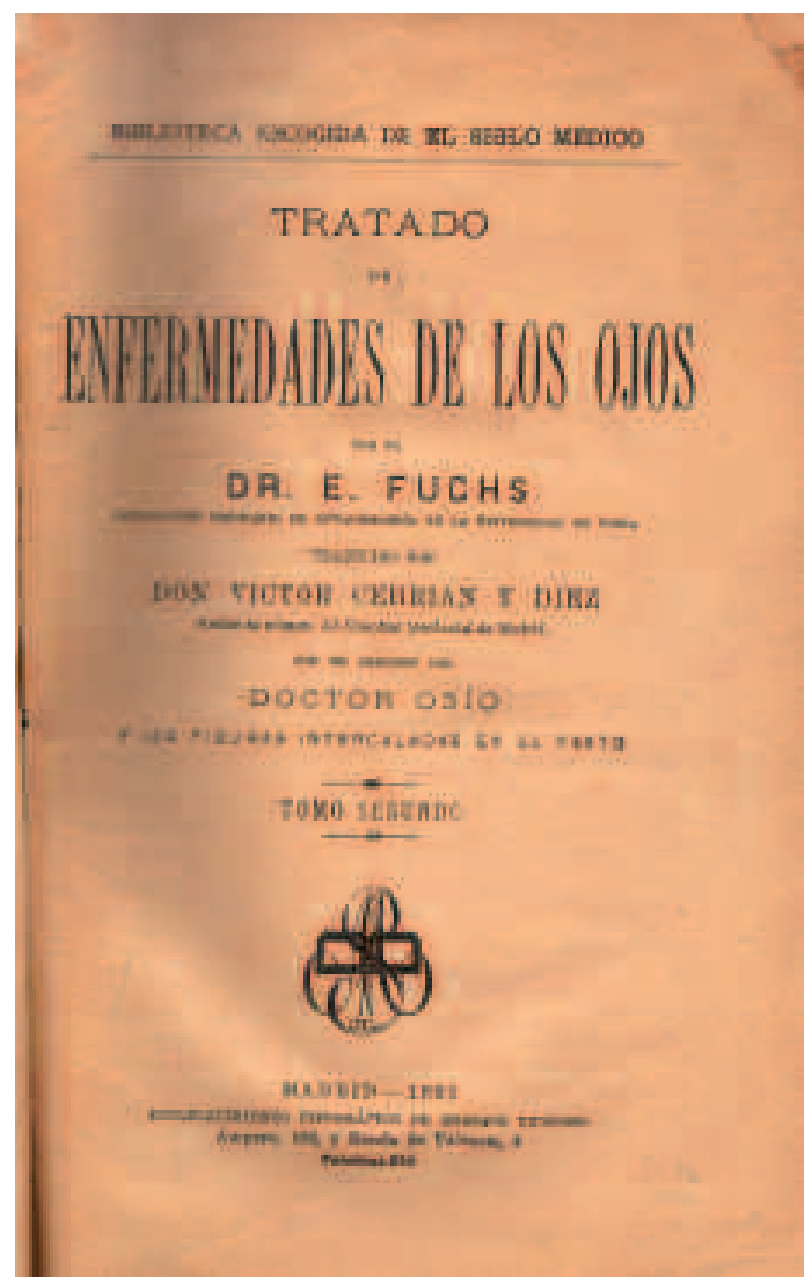

\footnotetext{
${ }^{1}$ Licenciado en Oftalmología. Hospital San Agustín de Avilés. Asturias. España.

E-mail: jjbarbon@telecable.es

2 Doctora en Oftalmología. Hospital Álvarez-Buylla de Mieres. Asturias. España.
} 
región papilar como en la retina propiamente dicha. La ceguera es definitiva. La embolia, en vez de interesar a la misma arteria central, puede obliterar solo alguna de sus ramas. En este caso, los cambios apreciables a la vista se limitan a la parte nutrida por el vaso obstruido. Así que la ceguera no alcanza más que a la parte enferma de la retina y se manifiesta bajo la forma de un vacío en el campo visual, del cual está abolido una mitad o un sector. Las embolias se observan en las afecciones que dan lugar a la formación de coágulos en el torrente circulatorio, principalmente en las enfermedades del corazón. La posibilidad de curación no existe sino en los casos absolutamente recientes, antes de que se haya necrosado la retina. Únicamente podría adquirir de nuevo sus funciones si se lograse restablecer la circulación, lo cual no puede suceder sino consiguiendo transportar el tapón que obtura la arteria central a sus ramas más pequeñas, en cuyo punto ocasiona menos trastornos. Con este objeto se evacua el humor acuoso por medio de una punción practicada en la córnea. Por la disminución brusca de la presión intraocular producida de este modo, la sangre tiende a afluir en mayor cantidad al ojo, lo cual puede empujar mas adelante el émbolo cuando no está muy sólidamente fijo. Al mismo tiempo, se trata de hacer avanzar por el amasamiento; y de esta manera, en un corto número de casos absolutamente recientes, se logra restablecer la circulación retiniana y, por consiguiente, la vista».

El fenómeno de la embolia de la arteria central de la retina había sido observado por primera vez por Albrecht von Graefe en 1859 en forma de «... una ceguera repentina determinada por la penetración de un coágulo en la arteria central de la retina», como bien nos lo describe Louis de Wecker (18321906) en el apartado dedicado a las Enfermedades de la retina y del nervio óptico de su extenso Tratado Teórico y práctico de las Enfermedades de los ojos, traducido al español por el Dr. Francisco Delgado Jugo y publicado en su 1. a edición en Madrid en 1870. Wecker fue uno de los grandes oftalmólogos de la segunda parte del s. XIX, que residió y trabajó en París, donde publicó la edición original en 1867-68. La descripción de Wecker no es tan brillante como la de Fuchs, aunque nos informa con detalle de estos primeros casos descritos en un tiempo en que la retina era un campo recién abierto al descubrimiento clínico gracias al invento del oftalmoscopio por Helmotz en 1850 y que el propio

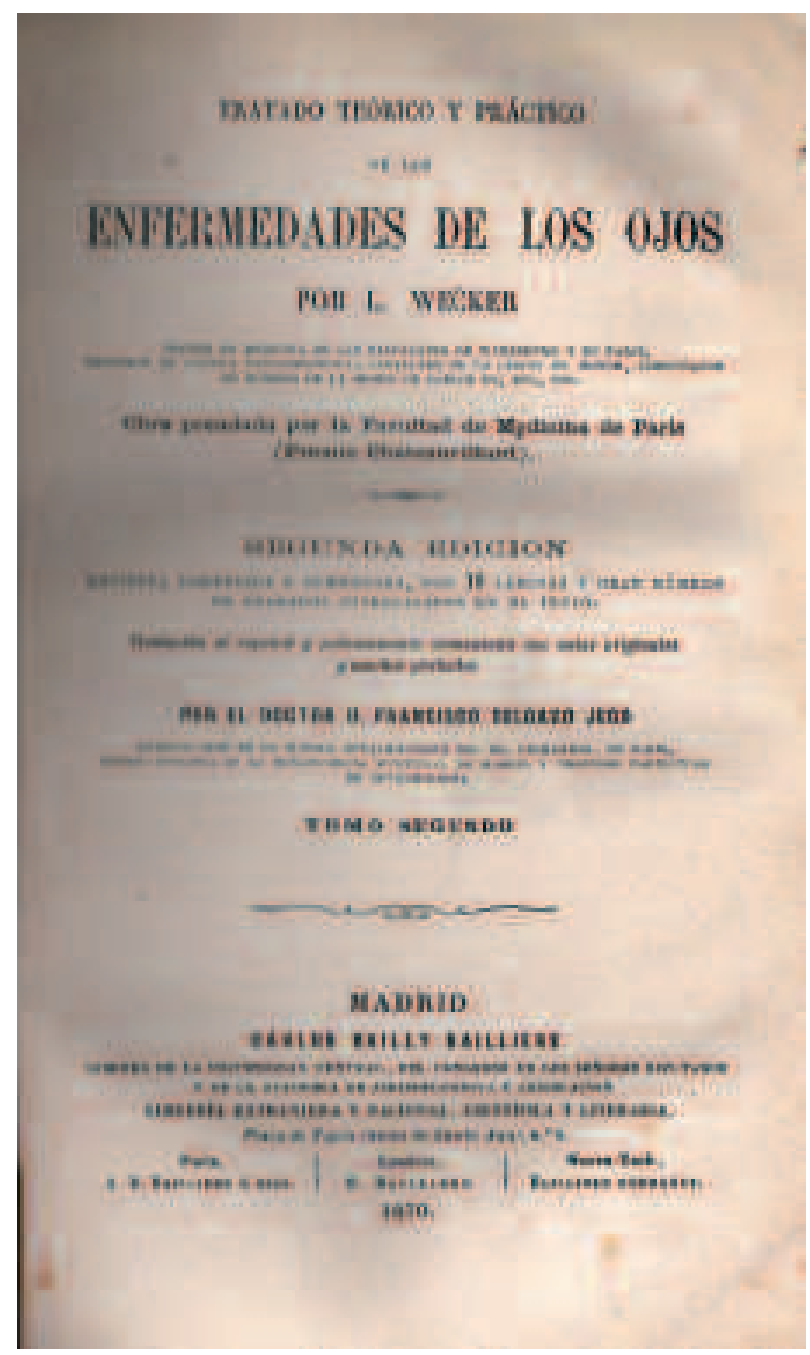

Wecker había introducido en Francia. «M. de Jaeger en 1854, había hablado de un caso de ceguera brusca, determinado por una detención de la circulación retiniana, pero sin pensar en explicarlo por una embolia o atascamiento. Después de la publicación de $M$. de Graefe fueron recogidas y publicadas casi una veintena de observaciones, bajo el nombre de embolia de arteria central de la retina». Con tan poca casuística y los métodos diagnósticos tan limitados sólo se consideraba la etiología cardiaca «En la mayor parte de los casos se había comprobado, de una manera irrecusable, la existencia de una alteración del corazón, que consistía frecuentemente en una alteración de las válvulas aórticas. En algunos enfermos fenómenos de embolia cerebral han seguido de cerca de la enfermedad ocular»; pero de forma notable, ya se expone el tratamiento que perdura hasta la actualidad: «... Vista 
la inocuidad de las paracentesis, siempre creemos permitido hacer de este medio un uso metódico y bastante prolongado».

Aunque ninguno de los múltiples tratamientos se ha demostrado claramente más efectivo que el curso natural del proceso obstructivo, el masaje ocular y la paracentesis persisten, después de más 130 años, como los mas utilizados en un intento precoz de restaurar la circulación arterial retiniana, para algún autor como Kansky los únicos aconsejados junto a la acetazolamida intravenosa. Los mecanismos de acción parecen ser, en el caso del masaje ocular, una elevación de la presión intraocular que puede dilatar las arterias retinianas incrementando el flujo sanguíneo, mientras que en la paracentesis se provoca un descenso brusco de la presión intraocular que puede desplazar al émbolo hacia ramas arteriales más distales. La gran dificultad técnica de otros tratamientos, parece que más efectivos, como la embolectomía mediante vitrectomía y la fibrino- lisis a nivel de la arteria oftálmica convierten en poco viables su aplicación extendida en la práctica clínica.

\section{BIBLIOGRAFÍA}

1. Fuchs E. Tratado de enfermedades de los ojos. Enfermedades de la retina. Madrid: Biblioteca Escogida de El Siglo Médico; 1893; Tomo II, Cap. 3: 67-68.

2. Wecker L. Tratado Teórico y práctico de las Enfermedades de los ojos. $2^{a}$ Ed. Madrid: Bailly-Bailliere; 1870; Tomo II: 847-854.

3. Sanborn GE, Magargal LE. Arterial obstructive diseases of the eye. In: Tasman, Jaeger. Duane's clinical ophthalmology on CD-ROM. Philadelphia: Lippincott, Williams \& Wilkins. 2003.

4. Kansky JJ. Clinical Ophthalmology. 4th ed. Oxford: Butterworth Heinemann; 1999; 486-491.

5. Cotallo de Cáceres JL, Hernández Benito E, Munoa Ruiz $J L$, Leoz de la Fuente G. Historia de la Oftalmología Española. Madrid: LXIX Ponencia de la Sociedad Española de Oftalmología; 1993. 